\title{
Quantifying the Incremental and Aggregate Cost of Missed Workdays in Adults with Diabetes
}

\author{
Kinfe G. Bishu, Ph.D. ${ }^{2}$, Mulugeta Gebregziabher, Ph.D. ${ }^{1,3}$, Clara E. Dismuke, Ph.D. ${ }^{1,2}$, and Leonard E. \\ Egede, M.D., M.S. ${ }^{1,2}$ \\ 'Health Equity and Rural Outreach Innovation Center, Ralph H. Johnson Department of Veterans Affairs Medical Center, Charleston, SC, USA; \\ ${ }^{2}$ Center for Health Disparities Research, Division of General Internal Medicine, Medical University of South Carolina, Charleston, SC, USA; \\ ${ }^{3}$ Department of Public Health Sciences, Medical University of South Carolina, Charleston, SC, USA.
}

OBJECTIVE: Although the national cost of missed workdays associated with diabetes has been estimated previously, we use the most recent available national data and methodology to update the individual and national estimates for the U.S population.

METHODS: We identified 14,429 employed individuals $\geq$ 18 years of age in 2011 Medical Expenditure Panel Survey (MEPS) data. Diabetes and missed workdays were based on self-report, and cost was based on multiplying the daily wage rate for each individual by the number of missed days. Adjusted total national burden of missed workdays associated with diabetes was calculated using a novel two-part model to simultaneously estimate the association of diabetes with the number and cost of missed workdays.

RESULTS: The unadjusted annual mean 2011 cost of missed workdays was \$277 (95\% CI 177.0-378.0) for individuals with diabetes relative to $\$ 160$ (95\% CI \$130-\$189) for those without. The incremental cost of missed workdays associated with diabetes was \$120 (95\% CI \$30.7-\$209.1). Based on the US population in 2011 , the unadjusted national burden of missed workdays associated with diabetes was estimated to be $\$ 2.7$ billion, while the fully adjusted incremental national burden was estimated to be $\$ 1.1$ billion.

CONCLUSIONS: We provide more precise estimates of the cost burden of diabetes due to missed workdays on the U.S population. The high incremental and total cost burden of missed workdays among Americans with diabetes suggests the need for interventions to improve diabetes care management among employed individuals.

KEY WORDS: diabetes; cost; work absenteeism.

J Gen Intern Med 30(12): 1773-9

DOI: $10.1007 / \mathrm{s} 11606-015-3338-\mathrm{y}$

(c) Society of General Internal Medicine 2015

Electronic supplementary material The online version of this article (doi:10.1007/s11606-015-3338-y) contains supplementary material, which is available to authorized users.

Received August 25, 2014

Revised December 24, 2014

Accepted March 31, 2015

Published online May 19, 2015
$\mathrm{D}$ iabetes is one of the fastest growing chronic diseases in the United States and globally. It has been shown to be associated with increased healthcare costs, disability, lost productivity and premature mortality. ${ }^{1,2}$ Diabetes is the seventh leading cause of death in the United States and it imposes a substantial direct and indirect cost burden on the U.S economy. ${ }^{3,4}$

In 2010, diabetes was estimated to affect 25.8 million people, or $8.3 \%$ of the US population. ${ }^{3}$ The prevalence among individuals aged 20 years or older has been increasing, which suggests that diabetes has become an important risk factor for the American workforce. ${ }^{3,5}$ Non-Hispanic Blacks (NHB), Hispanic, American Indians, and some Asian Americans are at particularly high risk for type 2 diabetes and its complications. . $^{1,3,6}$

Individuals with diabetes have been shown to have substantially higher rates of missed work, disability and probability of being early retired than those without diabetes. ${ }^{4,7,8}$ Based on 2000-2004 MEPS data, the combined job absenteeism costs of obesity, morbid obesity and diabetes were estimated to be $\$ 3.9$ billion annually. ${ }^{9}$ Costs associated with diabetes are estimated to have risen $41 \%$ from $\$ 174$ Billion ( $\$ 116$ billion direct cost and $\$ 58$ billion indirect cost) in $2007^{8}$ to $\$ 245$ Billion ( $\$ 176$ billion direct cost and $\$ 69$ billion indirect cost) in 2012. ${ }^{4}$ Loss of productivity has been shown to be increasing over time and has become a major concern to our nation's health system and for health policy. ${ }^{4,10}$

Previous studies have examined the association of diabetes with number and cost of missed workdays, work participation and productivity losses. ${ }^{4,7-13}$ There is a wide range of variation in the statistical models used to estimate incremental and aggregate cost of missed workdays for individuals with diabetes. ${ }^{4,7,9,10,13}$ The American Diabetes Association in 2012 used ordinary least square (OLS) regression with the 20092011 NHIS data, and showed that the annual cost of missed workdays per person with diabetes was $\$ 149$ and the aggregate cost of missed workdays was $\$ 5$ billion. ${ }^{4}$ Another ${ }^{7}$ used Health and Retirement Study data and a two-part model with OLS regression to examine the association of diabetes with the natural logarithm of income, and found that the average incremental lost income of sick days per person with diabetes was $\$ 630$ and aggregate incremental loss income of sick days was \$1.5 billion for 1992-2000. 
The statistical model used to evaluate the incremental cost of a disease can have a major impact on the findings, particularly in cost variables with excess zero values and a skewed distribution. ${ }^{14}$ Number of missed workdays and cost data are typically right-skewed because a relatively small proportion of patients miss extremely high number of workdays and incur high costs. Estimates from the linear regression models are known to lead to biased and unstable estimates due to the skewness and kurtosis of the data distribution and heteroscedasticity. ${ }^{13}$ For such problems, prior studies of diabetes and associations with work activities modeled the second part of the two-part model using OLS regression of logtransformed workdays or costs. ${ }^{7,9}$ Similarly, previous studies used a two-part model proposed by Duan based on homoskedastic, normally distributed errors and a nonparametric approach, which provides estimates in the original scale after some retransforming. ${ }^{14}$ However, this retransformation from $\log$ scale to the original scale leads to a potential underestimation or overestimation of the number of missed workdays and cost of missed workdays. ${ }^{14}$

To avoid such problems, we used a generalized linear model (GLM) model with log-link and gamma distribution in the second part of the two-part model. This study contributes to the literature on diabetes by estimating the incremental cost of missed workdays using this novel GLM approach.

\section{METHODS}

\section{Sample}

We analyzed the responses of 14,429 employed individuals age $\geq 18$ years, representing 150,378,648 individuals in 2011 consolidated data (HC-147) from the Medical Expenditure Panel Survey (MEPS). MEPS is an ongoing national household survey for the civilian non-institutionalized U.S. population. ${ }^{15}$ The data are collected through in-person interviews and include information on the respondents' health status, demographic and socio-economic characteristics, employment, missed workdays, access to care and satisfaction with healthcare. The survey collects comprehensive data on healthcare utilization and expenditure and has a complex survey design, which includes multistage sampling, clustering and stratification with oversampling of minorities. ${ }^{13}$

\section{Measures}

All variables used for analysis were based on self-report:

Diabetes. Diabetes indicates a yes response to the question "Have you ever been diagnosed with diabetes?" MEPS data does not distinguish between type I and type 2 diabetes. However, MEPS 2011 data showed that $79 \%$ of the respondents reported treating their diabetes with diet and oral medications, which suggests that most respondents have type 2 diabetes.
Missed Workdays. Missed workdays represent the number of times the person lost a half-day or more from work in 2011 because of illness, injury, mental or emotional problems during the study period. Because half-days and full-days lost were not distinguished in MEPS, all days lost were recorded as fulldays lost, which is consistent with previous studies that used MEPS data. ${ }^{9,16,17}$ A response of "no workdays lost" was coded as zero.

Cost of Missed Workdays. Annual cost of missed workdays was based on multiplying the daily wage of each respondent by the number of missed workdays. The daily wage rate was calculated by multiplying the non self-employed hourly wage rate by mean hours worked per day. Self-employed individuals were excluded from the analysis because hourly wage was not asked of the selfemployed. ${ }^{15}$ MEPS only collected data for usual hours worked per week, not hours worked per day. The mean hours worked per day was calculated by dividing usual hours worked per week by 5 days, similar to a previous MEPS study. ${ }^{17}$ To obtain the mean daily wage, we multiplied the mean hours worked per day by the hourly wage. To estimate the annual cost of missed workdays per individual, we multiplied mean daily wage by the annual missed workdays of the individual.

Comorbidities. Binary indicators of comorbidities were based on a positive response to the question "Have you ever been diagnosed with major depression, hypertension, coronary heart disease, angina, myocardial infarction, other heart diseases, stroke, emphysema, high cholesterol, joint pain, arthritis and asthma?" Self-reported comorbidities were used in order to control for confounding variables and examine their individual incremental effects on the number and cost of missed workdays in the fully adjusted regression. Previous studies showed that the binary indicators of disease are more effective in accounting for disease burden. ${ }^{18,19}$

\section{Demographic and Socioeconomic Characteristics}

Race/Ethnicity. MEPS defines race/ethnic groups as: White, Black, American Indian/Alaska Natives, Asian, Natives Hawaiian/Pacific Islander, Multiple race and Hispanic or not. We re-coded it into four groups: non-Hispanic White (NHW), non-Hispanic Black (NHB), Hispanic and other.

Education. Educational attainment was coded into four groups: less than high school $(\leq$ grade 11$)$, high school (grade 12), college (grade 13-16) and graduate school $(\geq$ grade 17).

Marital Status. Marital status was coded into three groups: married, not married (widowed/divorced/separated) and never married. 
Gender. Gender was coded with male as the reference group.

Age. Age was coded into four age groups: 18-24, 25-44, 4564 and $\geq 65$ years.

Census Region. Census region was coded as: Northeast, Midwest, South and West.

Metropolitan Statistical Area (MSA). Metropolitan Statistical Area (MSA) was based on living in an MSA as of December 2011.
Health Insurance Status. Health insurance was coded into three categories: private, public only and uninsured.

\section{Analyses}

We estimated a two-part GLM allowing ${ }^{20}$ for mixed discretecontinuous variables. In the first part of the two-part model, a probit model is estimated for the probability of observing a zero versus positive value for number and cost of missed workdays. Then, conditional on a positive value, the second part of the model was estimated with a GLM, gamma

Table 1 Sample Demographics by Diabetes Status Among Employed Adults, United States 2011

\begin{tabular}{|c|c|c|c|c|}
\hline \multirow{2}{*}{$\begin{array}{l}\text { Variables } \\
\mathrm{N} \text { (n) }\end{array}$} & \multirow{2}{*}{$\frac{\text { All }(\%)}{150,378,648(14,429)}$} & \multirow{2}{*}{$\frac{\text { Diabetes (\%) }}{9,746,298(1006)}$} & \multirow{2}{*}{$\frac{\text { No Diabetes }(\%)}{140,632,350(13,403)}$} & \multirow[t]{2}{*}{$p$ value } \\
\hline & & & & \\
\hline \multicolumn{5}{|l|}{ Age category (years) } \\
\hline Age $18-24$ & 10.8 & 0.7 & 11.4 & \multirow[t]{4}{*}{$<0.001$} \\
\hline Age $25-44$ & 43.1 & 19.4 & 44.8 & \\
\hline Age $45-64$ & 40.2 & 64.2 & 38.6 & \\
\hline Age $65-85$ & 5.9 & 15.7 & 5.2 & \\
\hline \multicolumn{5}{|l|}{ Gender } \\
\hline Male & 52.4 & 56.6 & 52.1 & \multirow[t]{2}{*}{0.03} \\
\hline Female & 47.6 & 43.4 & 47.9 & \\
\hline \multicolumn{5}{|l|}{ Race/ethnicity } \\
\hline Non-Hispanic White & 67.5 & 62.6 & 67.8 & \multirow[t]{4}{*}{$<0.001$} \\
\hline Non-Hispanic Black & 10.5 & 15.3 & 10.2 & \\
\hline Non-Hispanic Other & 7.0 & 6.7 & 7.1 & \\
\hline Hispanic & 15.0 & 15.4 & 14.9 & \\
\hline \multicolumn{5}{|l|}{ Marital status } \\
\hline Married & 56.0 & 62.0 & 55.6 & \multirow[t]{3}{*}{$<0.001$} \\
\hline Not married & 16.3 & 23.8 & 15.8 & \\
\hline Never married & 27.7 & 14.2 & 28.6 & \\
\hline \multicolumn{5}{|l|}{ Education category } \\
\hline$<$ HS & 9.7 & 12.0 & 9.6 & \multirow[t]{4}{*}{$<0.001$} \\
\hline HS & 26.5 & 34.0 & 26.0 & \\
\hline College & 49.5 & 45.6 & 49.7 & \\
\hline Graduate school & 14.3 & 8.4 & 14.7 & \\
\hline \multicolumn{5}{|l|}{ Insurance } \\
\hline Private & 78.7 & 80.7 & 78.5 & \multirow[t]{3}{*}{$<0.001$} \\
\hline Public & 6.6 & 9.4 & 6.4 & \\
\hline Uninsured & 14.7 & 9.9 & 15.1 & \\
\hline \multicolumn{5}{|c|}{ Metropolitan statistical status } \\
\hline MSA & 85.2 & 82.3 & 85.5 & \multirow{2}{*}{0.10} \\
\hline Non-MSA & 14.8 & 17.7 & 14.5 & \\
\hline \multicolumn{5}{|l|}{ Census region } \\
\hline Northeast & 18.1 & 16.8 & 18.2 & 0.05 \\
\hline Midwest & 22.6 & 23.3 & 22.5 & \\
\hline South & 36.5 & 41.3 & 36.2 & \\
\hline West & 22.8 & 18.6 & 23.1 & \\
\hline Income & & & & \\
\hline$\$ 1-\$ 24,999$ & 32.5 & 27.9 & 32.8 & 0.02 \\
\hline$\$ 25,000-\$ 49,999$ & 34.3 & 40.4 & 33.8 & \\
\hline$\$ 50,000-\$ 74,999$ & 17.4 & 16.1 & 17.5 & \\
\hline$\$ 75,000-\$ 296,955$ & 15.8 & 15.6 & 15.9 & \\
\hline Major depression & 5.9 & 10.8 & 5.5 & $<0.001$ \\
\hline Hypertension & 25.7 & 69.4 & 22.7 & $<0.001$ \\
\hline Coronary HD & 2.6 & 10.7 & 2.0 & $<0.001$ \\
\hline Angina & 1.1 & 4.7 & 0.9 & $<0.001$ \\
\hline Myocardial Infarction & 2.0 & 8.8 & 1.5 & $<0.001$ \\
\hline Other HD & 7.1 & 13.5 & 6.7 & $<0.001$ \\
\hline Stroke & 1.3 & 5.7 & 1.0 & $<0.001$ \\
\hline Emphysema & 0.8 & 1.4 & 0.8 & 0.06 \\
\hline High Cholesterol & 25.3 & 65.7 & 22.5 & $<0.001$ \\
\hline Joint pain & 26.8 & 47.2 & 25.4 & $<0.001$ \\
\hline Arthritis & 17.1 & 35.4 & 15.8 & $<0.001$ \\
\hline Asthma & 8.0 & 9.8 & 7.8 & 0.07 \\
\hline
\end{tabular}

$N$ weighted sample size, $n$ unweighted sample size 
distribution and log link for the positive values. ${ }^{14}$ To determine the family distribution for the GLM, we used the modified Park test. ${ }^{14,20}$ The results of the modified Park test verified that the use of a gamma distribution with a log link was the best-fitting GLM to get consistent estimation of coefficients and incremental effects. ${ }^{16}$ The gamma model is used for data situations in which the responses take only values greater than or equal to $0 .^{21}$ Cost data are typically right-skewed because a relatively small proportion of patents incur extremely high cost, and the GLM with log link and gamma variance function takes this problem into account. ${ }^{13}$ Since the dependent variables in our study were characterized by a high concentration of observations with zeros, we used the two-part GLM to improve the precision of the estimates. ${ }^{16}$ Recently, regression-based methods such as the two-part model, and GLM with gamma distribution and log link, have emerged as a standard for estimating the incremental cost attributable to disease or risk factors. ${ }^{14,16}$ We then generated number and cost of missed workday variables to estimate unadjusted and adjusted means.

In order to generalize the study findings to the U.S population, the complex sampling design of MEPS data set was taken into account by using the sampling weights, variance estimation stratum and primary sampling unit (clustering). The weighted two-part model was used to estimate the association of number and cost of missed workdays with diabetes, adjusting for demographic factors and comorbidities, and to estimate the total burden of diabetes associated with missed workdays and cost on the US population. All statistical analysis was conducted using STATA 13.

\section{RESULTS}

Table 1 shows the characteristics for employed U.S. adults. Of the employed adult sample, $6.9 \%$ reported having diabetes. The prevalence of diabetes was found to increase with age and presence of comorbidities, and varied by demographic and economic factors. The prevalence of diabetes tended to be higher for people in the middle and older age groups, NHBs, males and those who were married. Those with diabetes were more likely to be uninsured, to have lower income and more likely to have comorbid conditions.

Table 2 shows the unadjusted mean and cost of annual missed workdays for individuals with and without diabetes. The unadjusted annual mean number of missed workdays per person was found to be 1.9 (95\% CI 1.3-2.6) for individuals with diabetes and 1.0 (95\% CI 0.87-1.1) for individuals without diabetes. The difference of annual mean number of missed workdays per person between the diabetes and no diabetes groups was about 0.90 days. The unadjusted annual mean cost of missed workdays per person per year was $\$ 277$ (95\% CI \$177-\$378) for the diabetes group and \$160 (95\% CI \$130-\$189) for those without diabetes. The difference in
Table 2 Means and Proportions of Missed Workdays and Cost of Missed Workdays by Diabetes Status, United States 2011

\begin{tabular}{|c|c|c|c|c|c|}
\hline \multirow[t]{2}{*}{ Variables } & \multicolumn{2}{|c|}{ Diabetes } & \multicolumn{2}{|c|}{ Non-diabetes } & \multirow{2}{*}{$\begin{array}{l}p \\
\text { value }\end{array}$} \\
\hline & Mean & $\begin{array}{l}95 \% \\
\text { CI }\end{array}$ & Mean & $\begin{array}{l}95 \% \\
\text { CI }\end{array}$ & \\
\hline $\begin{array}{l}\text { Annual missed } \\
\text { workdays }\end{array}$ & 1.9 & $\begin{array}{l}1.3- \\
2.6\end{array}$ & 1.0 & $\begin{array}{l}0.87- \\
1.1\end{array}$ & 0.007 \\
\hline Hourly wage rate & 19.6 & $\begin{array}{l}18.3- \\
207\end{array}$ & 20.2 & $\begin{array}{l}19.7- \\
205\end{array}$ & 0.33 \\
\hline $\begin{array}{l}\text { Hours worked per } \\
\text { week }\end{array}$ & 38.9 & $\begin{array}{l}37.7- \\
39.9\end{array}$ & 38.2 & $\begin{array}{l}37.8- \\
38.5\end{array}$ & 0.27 \\
\hline $\begin{array}{l}\text { Hours worked per } \\
\text { day }\end{array}$ & 7.8 & $\begin{array}{l}7.5- \\
7.9\end{array}$ & 7.6 & $\begin{array}{l}7.5- \\
7.7\end{array}$ & 0.27 \\
\hline Daily earning & 156 & $\begin{array}{l}144- \\
168\end{array}$ & 162 & $\begin{array}{l}159 \\
166\end{array}$ & 0.28 \\
\hline $\begin{array}{l}\text { Annual cost of } \\
\text { missed workdays }\end{array}$ & 277 & $\begin{array}{l}177- \\
378\end{array}$ & 160 & $\begin{array}{l}130- \\
189\end{array}$ & 0.02 \\
\hline
\end{tabular}

annual mean cost of missed workdays per person per year between the diabetes and no diabetes groups was about $\$ 117$.

Table 3 shows the incremental effect from the probit and GLM equations of the two-part model for the association between the number of missed workdays and diabetes after adjustment for covariates. After adjusting for other factors, having diabetes was associated with 0.84 (95\% CI 0.10-1.57) more missed workdays compared to similar individuals without diabetes. Women missed more workdays than men. Compared to NHW, NHBs missed less workdays. Compared to those with less than a high school education, individuals with a college degree missed less workdays. Compared to those privately insured, uninsured workers missed less workdays. Compared to those with no comorbidities, workers that had myocardial infarction, joint pain, arthritis and asthma missed more workdays.

Table 4 shows the incremental effect from both the probit and GLM version of the two-part model for the association of cost of missed workdays with diabetes and covariates. After adjusting for other factors, those with diabetes had \$120 (95\% CI \$30.7-\$209.1) higher cost of missed workdays. Women had $\$ 48$ higher cost of missed workdays. NHB had \$59 lower cost of missed workdays compared to NHW. Compared to those with private insurance, uninsured workers had $\$ 98$ lower cost of missed workdays. Compared to those with less than $\$ 25,000$, cost of missed workdays was $\$ 56$ higher in those who earned $\$ 25,000-\$ 49,999, \$ 146$ higher in those who earned \$50,000-\$74,999, and \$201 higher in those who earned $\$ 75,000-\$ 296,955$. Among those with chronic conditions, cost of missed workdays was $\$ 110$ higher in those with asthma, \$107 higher in those with arthritis, \$96 lower in those with emphysema, $\$ 80$ higher in those with joint pain, but $\$ 47$ lower in those with high cholesterol. Based on the nationally representative employed diabetes population $(9,774,612)$ in 2011, the unadjusted aggregate cost of missed workdays for the employed population in U.S with diabetes was estimated to be approximately $\$ 2.7$ billion and the adjusted incremental burden was estimated to be $\$ 1.1$ billion. 
Table 3 Two-Part Regression Model: Incremental Effect of Missed Workdays by Diabetes Status Accounting for Missed Workdays, United States 2011

\begin{tabular}{|c|c|c|c|}
\hline Variables & $\begin{array}{l}\text { Incremental } \\
\text { effect }\end{array}$ & $95 \% \mathrm{CI}$ & $p$ value \\
\hline Diabetes & $0.84 * *$ & $0.10-1.57$ & 0.02 \\
\hline Age $25-44$ & 0.16 & $-0.49-0.82$ & 0.62 \\
\hline Age 45-64 & -0.07 & $-0.84-0.70$ & 0.85 \\
\hline Age $65-85$ & -0.31 & $-1.40-0.76$ & 0.56 \\
\hline Female & $0.55 * * *$ & $0.23-0.87$ & 0.001 \\
\hline NH Black & $-0.57 * * *$ & $\begin{array}{l}-0.98- \\
-0.16\end{array}$ & 0.006 \\
\hline NH Others & -0.36 & $-0.87-0.14$ & 0.16 \\
\hline Hispanic & -0.38 & $-0.87-0.09$ & 0.11 \\
\hline Not married & 0.10 & $-0.34-0.55$ & 0.65 \\
\hline Never married & -0.23 & $-0.60-0.12$ & 0.20 \\
\hline High school & -1.12 & $-2.35-0.10$ & 0.07 \\
\hline College & -1.14 & $-2.37-0.08$ & 0.06 \\
\hline Graduate school & $-1.51 * *$ & $\begin{array}{l}-2.73- \\
-0.29\end{array}$ & 0.01 \\
\hline Public insured & 0.96 & $-0.07-1.99$ & 0.06 \\
\hline Uninsured & $-0.50 * * *$ & $\begin{array}{l}-0.83- \\
-0.18\end{array}$ & 0.002 \\
\hline $\begin{array}{l}\text { Metropolitan statistical } \\
\text { area }\end{array}$ & -0.03 & $-0.57-0.50$ & 0.90 \\
\hline Midwest & -0.38 & $-0.90-0.13$ & 0.14 \\
\hline South & 0.01 & $-0.54-0.57$ & 0.95 \\
\hline West & -0.14 & $-0.65-0.36$ & 0.57 \\
\hline$\$ 25,000 / 49,999$ & -0.02 & $-0.41-0.35$ & 0.88 \\
\hline$\$ 50,000 / 74,999$ & 0.09 & $-0.41-0.61$ & 0.70 \\
\hline$\$ 75,000 / 296,955$ & -0.27 & $-0.78-0.23$ & 0.28 \\
\hline Major depression & 0.86 & $-0.14-1.87$ & 0.09 \\
\hline Hypertension & 0.45 & $-0.01-0.93$ & 0.06 \\
\hline Coronary heart disease & -0.14 & $-1.06-0.77$ & 0.75 \\
\hline Angina & -0.18 & $-1.45-1.08$ & 0.77 \\
\hline Myocardial Infarction & $1.95^{* *}$ & $0.17-3.73$ & 0.03 \\
\hline Other heart disease & 0.46 & $-0.22-1.15$ & 0.18 \\
\hline Stroke & 0.39 & $-0.66-1.45$ & 0.46 \\
\hline Emphysema & $-1.12 * * *$ & $\begin{array}{l}-1.71- \\
-0.52\end{array}$ & $<0.001$ \\
\hline High cholesterol & -0.26 & $-0.68-0.14$ & 0.20 \\
\hline Joint pain & $0.60^{* * *}$ & $0.19-1.01$ & 0.004 \\
\hline Arthritis & $1.0 * * *$ & $0.42-1.58$ & 0.001 \\
\hline Asthma & $1.0 * *$ & $0.14-1.90$ & 0.02 \\
\hline
\end{tabular}

The 'margins' function in STATA is used to calculate incremental effects and their standard errors from the combined first and second parts of the final model. ${ }^{14}$

$* *$ statistically significant at $p<0.01 ; * * *$ statistically significant at $p<0.001$

Appendices Tables 1 and 2 (available online) show the probability of non-zero number and cost of missed workdays, and the number and cost of missed workdays, based on fully adjusted estimates from the first and second parts of the twopart model, respectively.

\section{DISCUSSION}

Using novel methodology, this analysis provides updated information on the relationship between diabetes and missed workdays for the US population after controlling for important confounding factors. We found that $6.9 \%$ had diabetes, which is consistent with national estimates of $7 \%$ for diabetes in the US in 2012. ${ }^{4}$ Our estimate of missed workdays is consistent with the low range of previous studies reported in a recent systematic review, ${ }^{8}$ which showed that those with diabetes had 0.90-5.7 higher missed workdays than those without diabetes.
Table 4 Two-Part Regression Model: Incremental Effect of Cost of Missed Workdays by Diabetes Status Accounting for Cost of Missed Workdays, United States 2011

\begin{tabular}{|c|c|c|c|}
\hline Variables & $\begin{array}{l}\text { Incremental } \\
\text { effect }\end{array}$ & $95 \%$ CI & $p$ value \\
\hline Diabetes & $119.9 * * *$ & $30.7-209.1$ & 0.008 \\
\hline Age $25-44$ & 54.3 & $-16.6-125.3$ & 0.13 \\
\hline Age $45-64$ & 31.6 & $-54.5-117.8$ & 0.47 \\
\hline Age $65-85$ & -87.2 & $-179.4-4.9$ & 0.06 \\
\hline Female & $47.9^{* * *}$ & $12.5-83.3$ & 0.008 \\
\hline NH Black & $-59.5 * * *$ & $-96.4--22.7$ & 0.002 \\
\hline NH Others & -38.2 & $-88.9-12.5$ & 0.14 \\
\hline Hispanic & -17.6 & $-77.4-42.1$ & 0.56 \\
\hline Not married & -24.6 & $-69.4-20.0$ & 0.28 \\
\hline Never married & -36.6 & $-76.3-3.0$ & 0.07 \\
\hline High school & -17.2 & $-91.9-57.5$ & 0.65 \\
\hline College & 19.2 & $-59.3-97.8$ & 0.63 \\
\hline Graduate school & -22.6 & $-105.1-59.9$ & 0.59 \\
\hline $\begin{array}{l}\text { Public insured } \\
\text { P }\end{array}$ & 17.2 & $-76.9-111.5$ & 0.72 \\
\hline Uninsured & $-97.5 * * *$ & $\begin{array}{l}-130.5- \\
-64.5\end{array}$ & $<0.001$ \\
\hline $\begin{array}{l}\text { Metropolitan statistical } \\
\text { area }\end{array}$ & -23.1 & $-93.6-47.3$ & 0.52 \\
\hline Midwest & -41.0 & $-95.8-13.6$ & 0.14 \\
\hline South & -14.5 & $-72.2-43.0$ & 0.62 \\
\hline West & -26.0 & $-81.5-29.4$ & 0.38 \\
\hline$\$ 25,000 / 49,999$ & $55.8 * * *$ & $21.4-90.3$ & 0.001 \\
\hline$\$ 50,000 / 74,999$ & $145.7 * * *$ & $59.7-231.8$ & 0.001 \\
\hline$\$ 75,000 / 296,955$ & $201.2 * * *$ & $103.9-298.5$ & $<0.001$ \\
\hline Major depression & 73.4 & $-17.8-164.7$ & 0.11 \\
\hline Hypertension & 47.6 & $-6.7-102.0$ & 0.08 \\
\hline Coronary heart disease & -52.4 & $-132.5-27.5$ & 0.19 \\
\hline Angina & 59.8 & $-126.8-246.6$ & 0.53 \\
\hline Myocardial Infarction & 104.7 & $-56.6-266.0$ & 0.20 \\
\hline Other heart disease & 63.2 & $-14.7-141.3$ & 0.11 \\
\hline Stroke & 49.0 & $-72.9-171.0$ & 0.43 \\
\hline Emphysema & $-95.8 * * *$ & $\begin{array}{l}-161.3- \\
-30.4\end{array}$ & 0.004 \\
\hline High cholesterol & $-46.9 * *$ & $-89.9--4.0$ & 0.03 \\
\hline Joint pain & $79.5 * * *$ & $34.0-124.9$ & 0.001 \\
\hline Arthritis & $107.0 * * *$ & $35.1-178.9$ & 0.004 \\
\hline Asthma & $109.6^{* *}$ & $1.7-217.6$ & 0.04 \\
\hline
\end{tabular}

Other studies reported more missing workdays for females. ${ }^{8,9,17,22}$ and conflicting evidence for minorities.

One study found NHBs had lower income, so that each day missed from work imposed a larger financial burden on the household. ${ }^{23}$ Others reported NHBs missing more workdays due to occupational illness or injury and fewer workdays due to influenza. ${ }^{17,24}$

Compared to those who were privately insured, we found uninsured workers had less missed workdays. There are higher out-of-pocket costs for uninsured employees to seek healthcare, and therefore missing work when ill is more of a financial burden for the uninsured. There is mixed evidence from the literature, with one study showing that having sick pay benefit was significantly associated with missed workdays. ${ }^{17,22}$ Another study reported that having health insurance was significantly associated with a decreased likelihood of missed workdays, but access to care was significantly associated with a greater number of missed workdays, and healthcare use was significantly associated with an increased likelihood of and greater number of missed workdays. ${ }^{22}$ Studies have noted in their limitations being unable to test if 
healthcare use and a chronic condition is endogenous with missed workdays. ${ }^{22,25}$ In our study, healthcare use is not incorporated within the study model, and future research needs to confirm the relationship among access to care, healthcare use and missed workdays to better understand the association of health insurance and missed workdays.

Our study estimated the cost burden of missed workdays for individuals with diabetes to be approximately $\$ 2.7$ billion, which is lower than a previous study that estimated the absenteeism cost for employed individuals with diabetes in the year 2012 to be about $\$ 5$ billion. ${ }^{4}$ However, the previous study was based on a number of different databases and included lost productivity and disability as well as missed workdays. ${ }^{4}$ The prevalence of diabetes is increasing in the US population. ${ }^{5,9,26}$ The economic burden associated with diabetes is likely to increase as diabetes becomes more prevalent. ${ }^{5}$ With rising prevalence of diabetes in the US, cost of missed workdays will continue to rise, and quantifying the incremental and aggregate cost of missed workdays is believed to be important to employers, to estimate potential cost savings of minimizing job absenteeism, along with interventions to reduce diabetes. Unless concerted efforts are undertaken, the economic burden of diabetes will continue to rise by contributing to work loss through absenteeism and health-related work limitations in the workplace. ${ }^{5}$ In addition, our findings suggest that disparities of missed workdays based on gender will assist policy makers to consider further efforts to improve women's health, thereby reducing the economic burden to women associated with missed workdays due to injury/illness.

Key strategies to reduce missed workdays in people with diabetes include improving the clinical care of diabetes, increasing medication adherence, reducing complications and treating comorbid mental illnesses such as depression. Namely, adding laypersons to the primary care team of individuals with diabetes improved having a retinal examination, microalbuminuria testing, and pneumonia vaccination. ${ }^{27}$ Likewise, a pharmacist-provided medication therapy management intervention reduced A1c levels on average by 0.27 from their baseline values. $^{28}$

Our study has a number of limitations. First, diabetes and comorbidity conditions were based on self-report, which was not verified clinically and may underestimate the findings. However, previous studies acknowledged the reliability of self-reported diabetes as a measure of diagnosis to provide unbiased estimates. ${ }^{12,29,30}$ Second, the cost of missed workdays estimates are for those individuals with diabetes and exclude the cost of missed workdays associated with family members who missed work to care for family members with diabetes. Hence, the associated cost of diabetes due to missed workdays may underestimate the true national cost estimates. Third, missed workdays and cost of missed workdays for the coexistence of diabetes and any comorbidity may differ from diabetes alone. It may be those comorbidity risk factors associated with uncontrolled diabetes, rather than diabetes itself, which are contributing to lost worked days. Fourth, the analysis was based on cross-sectional studies that are not dynamic. Therefore, longitudinal studies need to be conducted for further research that captures the changes over time. Fifth, we did not test for endogeniety and potential mediation in our model to validate the association between health insurance coverage with missed workdays and race/ethnicity with missed workdays, respectively. ${ }^{22}$

Despite these limitations, this study has important implications. Several previous studies assessed different areas of research of the association between productivity loss and socio-demographic characteristics in individuals with diabetes. ${ }^{4,5,8,9,13}$ However, we employed a novel two-part model to update previous MEPS estimates while accounting for the likelihood of having any missed workdays and the skewed distribution of cost of missed workdays. The aggregate cost of missed workdays was estimated be about $\$ 2.7$ billion in adults with diabetes in the U.S population. Future research is needed to identify the best interventions to reduce missed workdays in employed individuals with diabetes and determine whether workplace interventions have a role.

Acknowledgements: Authors' Contributions: Study concept and design: Dr. Bishu, Dr. Dismuke and Dr. Egede

Acquisition of data: Dr. Bishu and Dr. Egede

Analysis and interpretation of data: Dr. Bishu, Dr. Gebregziabher and Dr. Egede

Drafting of the manuscript: Dr. Bishu, Dr. Gebregziabher, Dr. Dismuke and Dr. Egede

Critical revision of the manuscript for important intellectual content: Dr. Bishu, Dr. Dismuke, Dr. Gebregziabher and Dr. Egede

Final approval of manuscript: Dr. Bishu, Dr. Dismuke, Dr. Gebregziabher and Dr. Egede

Funding/Financial Support: 1. This study was supported by Grant K24DK093699-01 from The National Institute of Diabetes and Digestive and Kidney Disease (PI: Leonard Egede). The funding agency did not participate in the design and conduct of the study; collection, management, analysis, and interpretation of the data; and preparation, review, or approval of the manuscript.

2. The manuscript represents the views of the authors and not those of the VA or HSR\&D.

3. Drs. Leonard E Egede, Kinfe Bishu and Mulugeta Gebregziabher are the guarantor's of this work, and as such, had full access to all the data in the study and take responsibility for the integrity of the data and the accuracy of the data analysis.

Conflict of Interest: The authors declare no conflicts of interest.

Corresponding Author: Leonard E. Egede, M.D., M.S.; Center for Health Disparities Research, Division of General Internal Medicine, Medical University of South Carolina, 135 Rutledge Avenue, MSC 593, Charleston, SC 29425 - 0593, USA (e-mail: egedel@musc.edu).

\section{REFERENCES}

1. Egede LE, Simpson K. Epidemiology, treatment and costs of depression in adults with type 2 diabetes. Expert Rev Pharmacoecon Outcomes Res. 2003;3(3):251-262.

2. Storm J, Egede EL. Impact of social support on outcomes in adult patients with Type 2 diabetes: a systematic review. Curr Diab Rep. 2012;12(6):769-781

3. National Diabetes Statistics 2011. http://diabetes.niddk.nih.gov/dm/ pubs/statistics/\#fast. 
4. American Diabetes Association. Economic costs of diabetes in the U.S in 2012. Diabetes Care. 2013;36:1033-1046.

5. Tunceli K, Bradley CJ, Nerenz D, Williams K, Pladevall M, Lafata JE. The impact of diabetes on employment and work productivity. Diabetes Care. 2005;28(11):2662-2667.

6. Chatter R, Edelman D, Selvin E. Non-traditional risk factor are important contributors to the racial disparity in diabetes risk: the atherosclerosis risk in communities study. J Gen Intern Med. 2014;29(2):290-297.

7. Vijan S, Hayward RA, Langa KM. The impact of diabetes on workforce participation: results from a national household sample. Health Serv Res. 2004;39(6): 1653-1670.

8. Breton M-C, Guenette L, Amiche MA, Kayibanda J-F, Grégoire J-P, Moisan J. Burden of diabetes on the ability to work. Diabetes Care. 2013;36:740-749.

9. Cawley J, Rizzo J, Haas K. The association of diabetes with job absenteeism costs among obese and morbidly obese workers. J Occup Environ Med. 2008;50(5):527-534.

10. Ng YC, Jacobs P, Johnson JA. Productivity losses associated with diabetes in the U.S. Diabetes Care. 2001;24:257-261.

11. Skerjanc A. Sickness absence in diabetic employees. Occup Environ. 2001;58:432-436.

12. Egede EL. Effects of depression on work loss and disability bed days in individuals with diabetes. Diabetes Care. 2004;27(7):1751-1753.

13. Fu AZ, Giu Y, Radican L, Wells BJ. Healthcare and productivity costs associated with diabetic patients with macrovascular comorbid conditions. Diabetes Care. 2009;32(12):2187-2192.

14. Belotti F, Deb P, Manning WG, Norton EC. Tpm: estimating two-part models. Stata J. 2012;5(2): 1-13.

15. Agency for Healthcare Research and Quality. Medical Expenditure Panel Survey. 2011 Full year consolidated data file 2013, Available from http:// meps.ahrq.gov/mepsweb/data_stats/download_data/pufs/h147/ h147doc.pdf. Accessed 5 April 2014.

16. Barnett SBL, Nurmagambetov TA. Costs of asthma in the United States: 2002-2007. J Allergy Clin Immunol. 2011;127(1):145-152.

17. Akazawa M, Sindelar JL, Paltiel AD. Economic costs of influenza-related work absenteeism. Value Health. 2003;6(2):107-115.

18. Egede LE, Lynch CP, Gebregziabher M, Hunt KJ, Echols C, Gilbert GE, Mauldin PD. Differential impact of longitudinal medication non-adherence on mortality by race/ethnicity among veterans with diabetes. J Gen Intern Med. 2012;28(2):208-215.

19. Egede LE, Gebregziabher M, Echols C, Lynch CP. Longitudinal effects of medication nonadherence on glycemic control. Ann Pharmacother. 2014;48(5):562-570.

20. Manning WG, Mullahy J. Estimating log models: to transform or not to transform? J Health Econ. 2001;20:461-494.

21. Hardin JW, Hilbe JM. Generalized linear models and extensions. 2nd ed. Texas: A Stata Press Publication, StataCorp LP College Station; 2007.

22. Lofland JH, Frick KD. Effect of health insurance on workplace absenteeism in the U.S. workforce. J Occup Environ Med. 2006;48:13-21.

23. Murray LR. Sick and tired of being sick and tired: scientific evidence, methods, and research implications for racial and ethnic disparities in occupational health. Am J Public Health. 2003;93:221-226.

24. Strong LL, Zimmerman FJ. Occupational injury and absence from work among African American, Hispanic, and Non-Hispanic white workers in the National Longitudinal. Survey of youth. Am J Public Health. 2005;95:1226-1232.

25. Rizzo JA, Abbott TA III, Berger ML. The labor productivity effects of chronic backache in the United States. Med Care. 1998;36:14711488.

26. Boyle JP, Thompson TJ, Gregg EW, Barker LE, Williamson DF. Projection of the year 2050 burden of diabetes in the US adult population: dynamic modeling of incidence, mortality, and prediabetes prevalence. Popul Health Metrics. 2010;8:29.

27. Adair R, Wholey DR, Christianson J, White KM, Britt H, Lee S. Improving chronic disease care by adding laypersons to the primary care team. Ann Intern Med. 2013;159:176-184.

28. Pinto SL, Kumar J, Partha G, Bechtol RA. Pharmacist-provided Medication Therapy Management (MTM) program impacts outcomes for employees with diabetes. Popul Health Manag. 2014;17(1):21-27.

29. Bush TL, Miller SR, Golden AL, Hale WE. Self-report and medical record report agreement of selected medical conditions in the elderly. Am J Public Health. 1980;79:1554-1556.

30. Harlow SD, Linet MS. Agreement between questionnaire data and medical records: the evidence for accuracy of recall. Am J Epidemiol. $1989 ; 129: 233-248$ 